\title{
IMPLEMENTING MEDICAL PROFESSIONALS' GUIDELINE DISCHARGE COUNSELING FOR ABORTIVE WOMEN VERSUS TRADITIONAL INSTRUCTIONS Nagwa El-Feshawy ${ }^{1}$, Hanan Elsayed Mohamed Elsayed ${ }^{2}$, Tyseer Marzouk $^{3}$, Amina El-Nemer ${ }^{4}$ \\ 1 Assistant lecturer of woman's Health \& Midwifery Nursing, Faculty of Nursing, Mansoura University, Egypt. 2Assistant Professor of woman's Health and Midwifery Nursing, Faculty of Nursing, Mansoura University, Egypt. 3Assistant Professor of woman's Health and Midwifery Nursing, Faculty of Nursing, Mansoura University, Egypt. 4 Professor of woman's Health and Midwifery Nursing, Faculty of Nursing, Mansoura University, Egypt. E.mail address : nagwa_ibrahim31@yahoo.com
}

Abstract:

The current study aimed to implement discharge counseling for abortive women using medical professionals' guidelines versus traditional instructions. Design: A quasiexperimental research design was used at the Labor and delivery room of Mansoura University Hospital. A purposive sample of 106 post abortion women, assigned to intervention group $(n=53)$ received care based on medical professionals' guidelines for care of woman with intrauterine fetal demise and control group $(n=53)$ receive conventional care of abortion. Data were collected using three tools; a structured interview questionnaire, Perinatal Grief Scale and satisfaction scale. Results: The intervention group had lower grief and higher satisfaction score compared to those of the control group $(51.58 \pm 7.18$ vs. $86.04 \pm 13.99 \& 108.15 \pm 6.29$ vs. $47.30 \pm 1.88$; $\mathrm{p}<0.001$ respectively). Conclusion and recommendations: Discharge counseling according to medical professionals' guidelines had a positive effect on alleviating post abortion grief and improving woman's satisfaction with the provided care. Accordingly, discharge counseling should be an integral part of nursing process after abortion to improve overall quality of care

Keywords: abortion, discharge counseling, medical professionals' guidelines

\section{Introduction:}

Abortion is the most common recognized pregnancy loss that occurred before 22 weeks of gestation ${ }^{(1)}$. It is a sensitive and contentious issue with religious, moral, cultural, and political dimensions. It is also a public health concern in many parts of the world. Globally, abortion-related deaths account for $13 \%$ of all pregnancy-related deaths, it is reported that in many countries of Africa, unsafe abortions are responsible for as much as $50 \%$ of maternal deaths (2\&3).

Women in developed and developing regions of the world had abortion at similar rates; annually, 29 abortions are performed per 1,000 women in developing countries, compared with 26 per 1,000 women in developed countries (4). In developing countries, two in five unsafe abortions occur among women under age of 25 years and about one in seven women who have unsafe abortions is under age of 20 years ${ }^{(5)}$.

Improving maternal health was one of the Millennium Development Goals (MDG).Ensuring appropriate access to skilled attendant during abortion and childbirth was an important priority of Safe Motherhood Initiatives and achieving standard of care during pregnancy, labor and delivery ${ }^{(6)}$. Improving quality of care during abortion and applying standards of care and counseling during pregnancy and delivery had a great impact in reducing 
IMPLEMENTING MEDICAL PROFESSIONALS' etc...

and by substitution in this formula: $n=$ $(\mathrm{Z} 1-\alpha / 2+\mathrm{Z} 1-\beta)^{2} \sigma 1 \sigma 2 / \delta^{2}$. Where $\mathrm{n}=$ sample size, $Z 1-\alpha / 2=1.96, Z 1-\beta=0.842$, $\sigma 1 \sigma 2=\mathrm{SD}$ for each group, and $\delta=$ Expected difference to be detected between 2 groups from a previous study, at Alpha error 0.05 (significance 95\%) and Beta error $20 \%$ (power of the study $80 \%$ ). Accordingly, the total sample size was calculated as 106 post abortion women, divided into two groups.

\section{Control group $(n=53)$}

Received the conventional care for abortion; specifically, were subjected to medical evacuation using vaginal Misoprostol tablets or surgical evacuation of the conception products, or both according to their clinical findings and ultrasound reports. Thereafter, the woman assigned for discharge after two hours from uterine evacuation.

2. Intervention group $(\mathbf{n}=\mathbf{5 3})$

Received the previously described conventional care, in addition to discharge counseling based on medical professionals' guideline to care of woman with intra-uterine fetal demise.

Medical Professionals Guideline: The guideline was adapted from Bereavement Support Work team of The National SIDS and Infant Death Program Centre, (2002) ${ }^{(17)}$ : to provide care to the family who experiences perinatal loss, neonatal death, or other infant death. It consists of three main themes: emotional support; information provided and discharge recommendations.

\section{Tools of data collection}

Data was collected using three tools; structured questionnaire schedule, Perinatal Grief Scale and satisfaction scale with the care provided.

Tool I: Structured questionnaire schedule: It is designed by the researcher based on reviewing the related scientific literature. It covers the participants' general characteristics such as age, educational level, residence, telephone number, marital status, consanguinity of couples, occupation, physical activity, etc. Tool II: Perinatal Grief Scale (PGS): This scale was adopted from Lasker \&Toedter-Lori, 2001 ${ }^{(18)}$. It used to evaluate women grief following perinatal loss. It consists of 33 items divided into three domains; active grief, difficulty coping, and despair. Each domain includes 11 items and represented the women's response to grief. The domain Active Grief includes items that belong to the normal emotional reactions to the loss, as sorrow, missing the fetus and crying. The domain Difficulty Coping includes items that involve more complex emotional reactions and include the areas of social isolation, difficulty with normal life activities and with other people, lack of support, feelings of guilt and problems in marital relationship. It appears to indicate depression and withdrawal. The third domain, Despair encompasses long term effects of the loss and involves existential feelings of helplessness and hopelessness. This measure was translated into Arabic language and was completed by the participants.

\section{Scoring system}

Each item was assessed on a five point Likert scale, ranging from 1 to 5 , where 1 means strongly agree, 2 indicates to agree to some extent, 3 refers to un decided, 4 means disagree to some extent, and 5 means strongly disagree. The total PGS score is arrived at by first reversing all of the items except 11 and 33.By reversing the items, higher scores now reflect more intense grief. Then add the scores together. The result is a total scale consisting of 33 items with a possible range of 33-165.

Tool III: Satisfaction scale It is designed by the researcher based on reviewing the related scientific literature. It consists of four domains; attitude of health care providers, information provided, 
intervention provided and discharge recommendations. The attitude of health care providers consisted of seven items, indicated the way a provider communicates with client. Information provided, consisted of eight items stated the kind of information received regarding care. The intervention provided consisted of four items, stated the kind of intervention women received by health care personnel. The discharge recommendations consisted of seven items. Those items described woman's needs while she was being counseled and treated. This measure was not translated into Arabic language; as it was completed by the researcher.

\section{Scoring system}

Each item was evaluated on a five point Likert scale ranges from 1 to 5 , where 1 means strongly dissatisfied, 2 means dissatisfied, 3 refers to undecided, 4 means satisfied, while 5 reflects strong satisfaction. The total scale score ranges from 26 to 130, the higher score indicates higher level of women satisfaction about the provided care.

\section{Validity of the tools}

For conducting the current study, electronic approval was obtained from the author Lasker, 2001 ${ }^{(18)}$ to use PGS, which was professionally translated into Arabic by language expertise. Also, content validity of the study tools was confirmed by five expertise in specialty of the study; two in obstetric medicine field and three in maternity nursing. Based on expert's suggestions, minor modifications were done.

\section{Reliability of the tools}

The reliability of the Perinatal Grief Scale was assessed in previous study by Potvin et al., (1989) ${ }^{(19)}$. The total scale showed high reliability with Cronbach's alpha of 0.95 , while the values of Cronbach's alpha were $0.92,0.91$ and 0.86 respectively for the active grief, difficulty coping, and despair domains. The reliability of the satisfaction scale was assessed in the current study, giving a Cronbach's alpha of 0.92 and hence the questionnaires showed high reliability. Reliability of the Arabic version of PGS was assessed giving Cronbach's alpha of 0.919 . However, that of the satisfaction did not assessed as it taken as it is.

\section{Ethical considerations}

Ethical approval was obtained from Research Ethics Committee at the Faculty of Nursing, Mansoura University. An informed consent was obtained from each participant after explaining the aim of the study.

\section{Research process}

The process was conducted through three phases; preparation for the work, implementation of the intervention, and evaluation of the outcomes.

\section{Preparation for the work}

In this phase, official agreements were taken from the Ethics Committee of Nursing Faculty and concerned authorities in Mansoura University Hospital, and the intervention was explained to the Labor and Delivery unit staff. Thereafter, study measurements were prepared by the researcher after reviewing the related scientific literature, checked its validity and reliability and required modifications were done. Piloting was conducted on 11 potential participants, to test the practicability of the intervention and to estimate the time needed for data collection. According to the analysis of the pilot study, the time required for discharge counseling was 25-30 minutes. The women included in the pilot study were excluded from the total sample. Actual fieldwork was started in July 2016.

\section{Implementation phase}

On arrival to the hospital, all potential participants had received their medical management according to the setting protocol of care; specifically were subjected to medical evacuation using vaginal Misoprostol tablets or surgical 
IMPLEMENTING MEDICAL PROFESSIONALS' etc...

evacuation of the conception products, or both according to their clinical findings and ultrasound reports. Thereafter, the researcher provided a clear explanation about the study nature to each eligible post abortion woman and invited them to participate in the study. After their agreement to participate, they were screened to confirm that they were met the inclusion criteria. After that the researcher informed the participants about the purpose of the study and the time required for participation.

Once a written consent form was obtained from the participants in the study, each one was assigned either to the intervention group or to the control group. Group's assignment based on their time of arrival, where the first 53 eligible women were assigned to the control group, while the second 53 eligible women were assigned to the intervention group.

Then, the researcher explained and provided the tools which included the structured questionnaire and perinatal grief scale which were completed by each participant as an initial base line assessment.

Finally, the researcher provided all the participants with her contact information and asked for their phone numbers. The researcher informed the participants that contact information could be used for follow up data. The participants were informed that they could contact with the researcher at any time.

\section{The control group}

The control group received the routine hospital care after abortion. After two-four hours from uterine evacuation and stabilizing their health status of women, they assigned for discharge from hospital with no specific support related to their physical and psychological states. The control group exposed to all conditions as intervention group except the discharge counseling according to medical professional guide lines.

\section{The intervention group}

According to the medical professionals' guideline, each participant of the intervention group was isolated from the postpartum women and their neonates. Participants were allowed to spend time with their loss, holding, naming or taking pictures if possible. Once women condition became improved, the researcher implement discharge plan and counseling according to Medical Professional Guidelines which included three main themes:

\section{I - Emotional support}

The researcher provided appropriate aspect of emotional support to abortive women in order to help them to gain control over themselves and accommodate with their conditions. It included; therapeutic touch, eye contact , caring attitude ,actively listening to women questions, allow time to grief ,express their feelings and ask questions and answer them honestly. The researcher explained to women, and if possible her husband or other family members, about grieving process after their loss and told them that this process was normal after abortion. Also, the researcher provided emotional support, information and counseling that help the parent to cope with their grief . This task took about 25-30 minutes for each participant.

\section{II- Providing information}

The researcher provided the abortive women with the required information about their conditions .It included type of abortion; possible causes, treatment options that were provided to them. As well as, the researcher informed the abortive women about physical consequences that affect their body after abortion, danger signs that required immediate attention. This information help them in understanding what were happened to them and also help in alleviating their grief. Finally, the researcher provided a strict emphasis for 
the importance of post abortion investigations and examinations under supervision of the medical staff on duty. This task took about 20-30 minutes for each participant.

\section{III- Discharge recommendations}

The researcher provided the participants with the discharge recommendations and instructions that were important to them after discharged to home. The recommendations included importance of healthy diet, proper exercise that would be performed, return of menstruation, future pregnancy, and desired method of contraception and follow-up visits. In addition, the husband and family members were advised to provide the woman with a specific emotional support during the early period after discharge and stressed on post abortion investigations and follow-up to determine causes behind abortion. This task took about 20 minutes for each participant.

Considering Egyptian women's culture, the researcher designed a colored handbook in an appropriate style .It was designed after extensive reviewing of related literature about discharge plan and counseling after abortion. It was supplemented by photos to facilitate understanding of information and for more illustrations. Each woman in the intervention group was assigned a hand book. The handbook contained all the necessary information about discharge plan and counseling according to medical professional guide lines. Also, it would help women to revise or recall information at any time they wanted after discharge. The researcher used the colored hand book during implementation of discharge plan and counseling as a facilitator for transition of information to abortive women.

On discharge, participants of the intervention group received a colored handbook to strengthen the counseling and information given as well as discharge instructions.

\section{Outcomes evaluation}

The perinatal grief and satisfaction with care provided were the outcomes of the study. Perinatal grief scale was assessed at base line after receiving the medical care and again at two points of assessment; after $2 \& 6$ weeks.

After two weeks, the researcher conducted a follow up contact with women which aimed to reinforce previous information given during discharge .As well as, the researcher assessed PGS as the researcher gave the women in the study groups an Arabic version of perinatal grief scale to be completed on the follow up times. Finally, after 6 weeks post abortion, the researcher assessed PGS and satisfaction with care for the study groups. These forms filled through telephone interview. This interview spend about 15 minutes each time.

\section{Limitation of the study}

- The researcher faced one limitation during data collection. It was that there was no spare rooms for each post abortion woman to receive care away from the postpartum mothers and their babies. However, the researcher dealt with that limitation by using a curtain or parade to isolate the participant from others.

\section{Statistical analysis}

Data were analyzed with SPSS version 22. The normal of data was first tested with one-sample KolmogorovSmirnov test. Association between categorical variables was assessed by Chisquare test. When more than $25 \%$ of the cells have expected count less than 5, Fisher exact test was used. Continuous variables were presented as mean \pm SD (standard deviation) for parametric data. The two paired study groups were compared by using Student $\boldsymbol{t}$ test. Analysis Of Variance (ANOVA test) used for comparison of means of more than two 
IMPLEMENTING MEDICAL PROFESSIONALS' etc...

groups. Pearson correlation used for correlation between continuous parametric data. For all above mentioned statistical tests done, the threshold of significance is fixed at 5\% level (p-value). The results was considered significant when the probability of error is less than $5 \%$ ( $\mathrm{p}<$ $0.05)$, non-significant when the probability of error is more than $5 \%(\mathrm{p}>0.05)$, highly significant when the probability of error is less than $0.1 \%$ ( $p<0.001)$, and the smaller the $\mathrm{p}$-value obtained, the more significant are the results.

\section{RESULTS}

Table one presents demographic data for the study groups. The mean age of both groups was almost identical (26.92 vs.

27.33 respectively). The higher percentages of the intervention and control groups had secondary education level, were housewives, belonged to urban residence, married between 20-25 years, were not consanguine, and reported a daily working hours of eight or less.

Table two presents mean of the active grief domain for the study groups at baseline, two weeks and six weeks post intervention. It is clear that there was no statistical significant difference between the intervention and control groups at base line assessment $(\mathrm{p}=0.166)$, while there were highly statistical significant differences between the two groups at two and six weeks post intervention $(\mathrm{p}<0.001)$. Table three shows mean of the difficulty coping domain for the study groups at baseline, two weeks and six weeks post intervention. Despite that there was no statistical significant difference between the intervention and control groups at base line assessment $(p=0.643)$, there were highly statistical significant differences between the two groups after the intervention by two and six weeks assessment $(\mathrm{p}<0.001)$.

Table four clarifies mean of the despair domain for the study groups at baseline, two weeks and six weeks post intervention. There was a statistical significant difference between the two groups after two weeks and a highly statistical significant difference after six weeks post intervention $(p=0.040 \&$ $\mathrm{p}<0.001$ respectively).

Figure one reveals mean of the total perinatal grief scale scores for the intervention and control groups at baseline, two weeks and six weeks post intervention. There were highly statistical significant differences between two groups after two and six weeks from the intervention $(\mathrm{p}<0.001)$.

Table five presents a comparison of the total scores of satisfaction with the care provided among the intervention and control groups at the time of discharge. There was highly statistical significant differences between the studied groups for the four domains of the satisfaction with provided care; particularly the attitudes of the health care providers, the provided information and intervention, and recommendations given at the time of discharge $(\mathrm{p}<0.001)$. 
Nagwa El-Feshawy et. al.

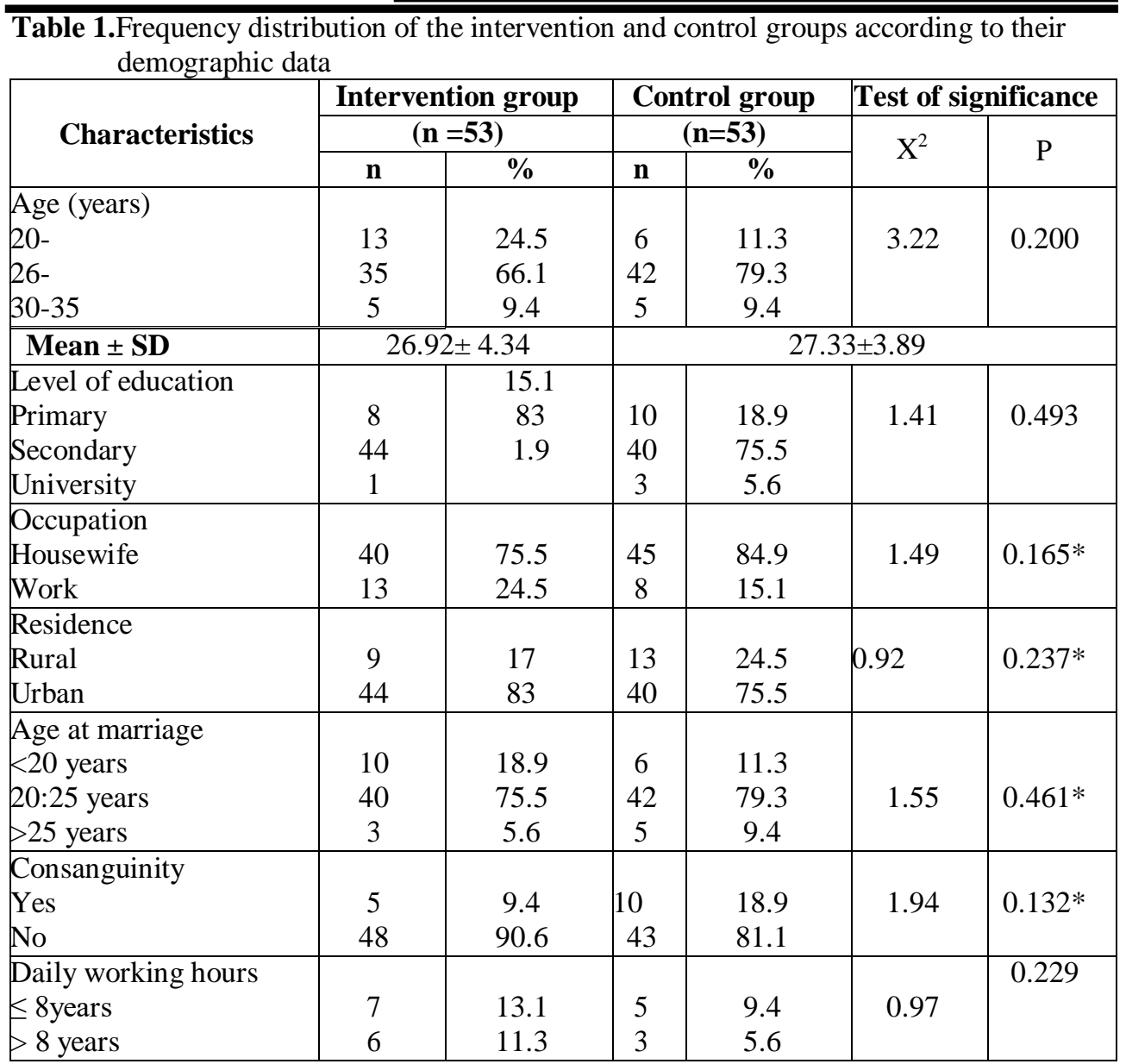

Table 2. Mean of the active grief domain for the intervention and control groups at baseline, and at two weeks and six weeks post intervention

\begin{tabular}{|c|c|c|c|c|}
\hline \multirow{2}{*}{$\begin{array}{c}\text { Active Grief Domain of } \\
\text { PGS }\end{array}$} & \multirow{2}{*}{$\begin{array}{c}\begin{array}{c}\text { Intervention group } \\
(n=53)\end{array} \\
\text { Mean } \pm \text { SD }\end{array}$} & \multirow{2}{*}{$\begin{array}{c}\begin{array}{c}\text { Control } \\
\text { group } \\
(\mathbf{n}=53)\end{array} \\
\text { Mean } \pm \text { SD } \\
\end{array}$} & \multicolumn{2}{|c|}{$\begin{array}{c}\text { Test of } \\
\text { significance }\end{array}$} \\
\hline & & & $\mathbf{T}$ & $\mathbf{P}$ \\
\hline At baseline & $41.64 \pm 1.21$ & $41.94 \pm 1.01$ & 1.395 & 0.166 \\
\hline \multicolumn{5}{|l|}{ Post the intervention by } \\
\hline Two weeks & $30.42 \pm 3.29$ & $35.36 \pm 2.35$ & 8.906 & $<0.001$ \\
\hline Six weeks & $18.4 \pm 2.86$ & $33.32 \pm 6.30$ & 15.701 & $<0.001$ \\
\hline $\mathrm{F}$ & 1048.404 & 69.895 & & \\
\hline $\mathrm{P}$ & $<0.001$ & $<0.001$ & & \\
\hline
\end{tabular}


IMPLEMENTING MEDICAL PROFESSIONALS' etc...

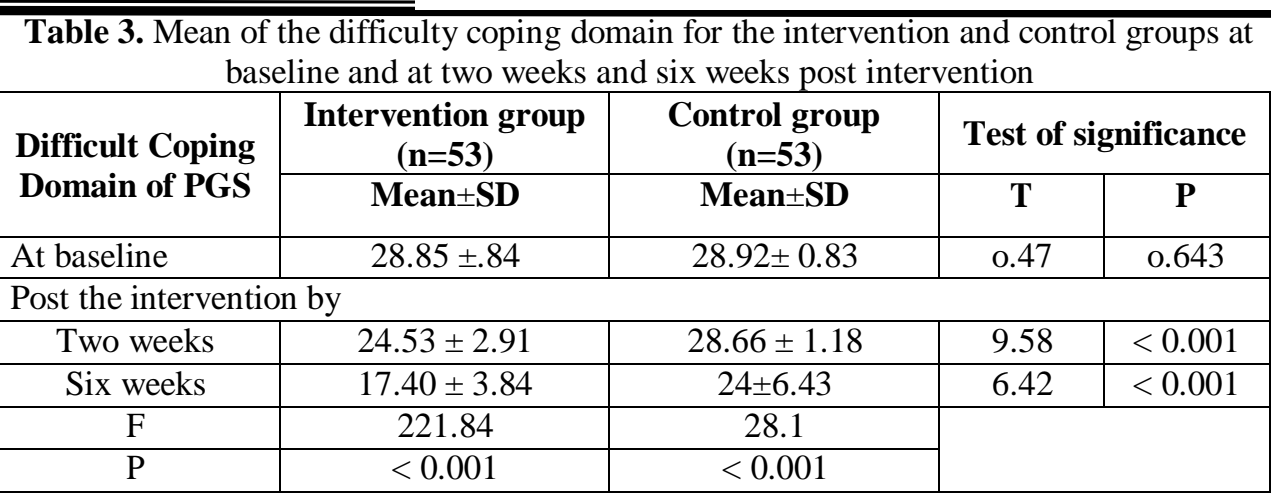

$t=$ Independent Samples Test and $F=A N O V A$ test

Table 4. Mean of the Despair domain for the intervention and control groups at baseline, two weeks and six weeks post intervention

\begin{tabular}{|c|c|c|c|c|}
\hline \multirow{2}{*}{$\begin{array}{c}\text { Despair Domain } \\
\text { of PGS }\end{array}$} & $\begin{array}{c}\text { Intervention group } \\
(\mathbf{n}=53)\end{array}$ & $\begin{array}{c}\text { Control group } \\
(\mathbf{n = 5 3})\end{array}$ & \multicolumn{2}{|c|}{ Test of significance } \\
\cline { 2 - 5 } & Mean \pm SD & Mean \pm SD & $\mathbf{t}$ & P \\
\hline At baseline & $41.11 \pm 1.78$ & $41.32 \pm 1.03$ & 0.73 & 0.465 \\
\hline Post the intervention by & $24.25 \pm 2.51$ & $26.13 \pm 6.10$ & 2.08 & 0.040 \\
\hline Two weeks & $15.79 \pm 3.21$ & $28.71 \pm 6.49$ & 12.99 & $<0.001$ \\
\hline Six weeks & 1336.8 & 130.6 & & \\
\hline F & $<0.001$ & $<0.001$ & & \\
\hline P & \multicolumn{5}{|l}{} \\
\hline
\end{tabular}

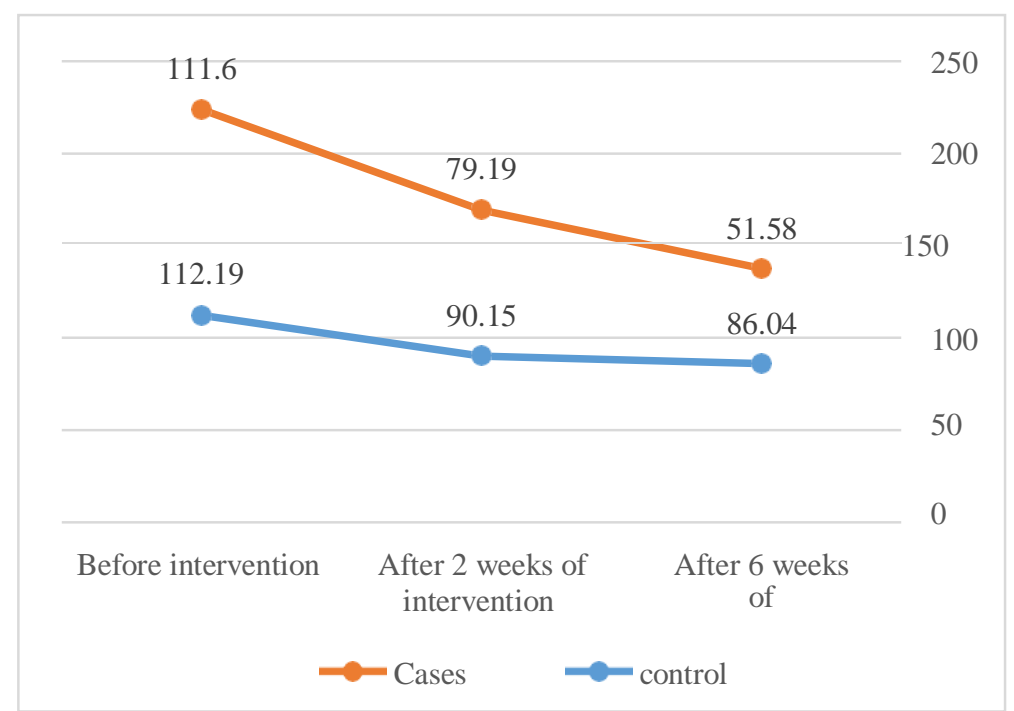

Figure 1. Mean difference of the total Perinatal Grief Scale scores among the intervention and control groups at baseline, two weeks and six weeks post intervention 
Nagwa El-Feshawy et. al.

Table5. Comparison of total scores of satisfaction with the care provided among the intervention and control groups after discharge

\begin{tabular}{|l|c|c|c|c|}
\hline \multicolumn{1}{|c|}{$\begin{array}{c}\text { Satisfaction } \\
\text { Domains }\end{array}$} & $\begin{array}{c}\text { Intervention group } \\
(\mathbf{n = 5 3 )}\end{array}$ & $\begin{array}{c}\text { Control group } \\
(\mathbf{n = 5 3 )}\end{array}$ & \multicolumn{2}{c|}{ Test of significance } \\
\cline { 2 - 5 } & Mean \pm SD & Mean \pm SD & $\mathbf{t}$ & $\mathbf{P}$ \\
\hline $\begin{array}{l}\text { Health care providers } \\
\text { attitude }\end{array}$ & $25.11 \pm 3.63$ & $19.55 \pm 1.38$ & 10.446 & $<0.001$ \\
\hline Information provided & $31.91 \pm 3.50$ & $14.21 \pm .41$ & 36.52 & $<0.001$ \\
\hline Intervention provided & $14.92 \pm 1.60$ & $4.62 \pm .88$ & 40.983 & $<0.001$ \\
\hline Discharge recommendation & $36.21 \pm 3.96$ & $8.92 \pm 1.17$ & 48.101 & $<0.001$ \\
\hline Total satisfaction score & $108.15 \pm 6.29$ & $47.30 \pm 1.88$ & 67.496 & $<0.001$ \\
\hline
\end{tabular}

\section{DISCUSSION}

The current study aimed to implement discharge counseling for abortive women using medical professionals' guidelines versus traditional instructions. This aim was supported by the present study findings. Such findings evidenced that participants of the intervention group; who received post abortion care according to the medical professionals' guidelines, reported a lower level of the total score of perinatal grief scale and a higher satisfaction scores with the care provided post abortion compared to those who received their post abortion care according to the conventional protocol of care.

The present study evaluated the perinatal Greif Scale by domains; specifically active grief, difficult coping and despair at the baseline and at the end of the $2^{\text {nd }}$ and $6^{\text {th }}$ weeks post intervention. It was evidences in this study, that there was no statistical significant differences for the PGS domains at the base line assessment between the intervention and the control groups, while, there were high statistical significant differences between the two groups after the $2^{\text {nd }}$ and $6^{\text {th }}$ weeks post intervention. Therefore, the first study hypothesis "Abortive women who receive post abortion care according to the medical professionals' guidelines, report lower scores of the perinatal grief compared to those receiving the conventional care", was supported.
The present study results supported that of Ridaura et al. (2017) (20) in a prospective analysis evaluated the grief symptomatology in a group of Spanish women at one month, six months and twelve months post abortion, such study found a significant reduction of the three domains of the PGS from the one month assessment values to the assessment values taken at six and twelve months.

Similarly, Sriarporn et al., (2017) (21) reported that there was no statistical significant difference between the intervention and control groups for the three PGS domains at the base line assessment. However, there were statistical significant differences between both groups after implementation of a support program. In the same line, Johnson \& Langford (2015) (16) reported significant differences between the three domains among the study group; which received bereavement intervention based on the medical professionals guidelines, also they experienced a lower level of grief and despair domains scores than the control group, which received the conventional care. This finding may be related to acquiring the woman's a chance for talking with reasonable persons, answering their questions, filling their gabs of misunderstanding, and providing support.

Inversely, the present study findings were dissimilarity with that of Murphy et al., (2012) ${ }^{(22)}$ in a previous study assessed 
IMPLEMENTING MEDICAL PROFESSIONALS' etc...

the effect of introducing counseling sessions on the psychological well-being of post abortion women. Such study reported that the counseling sessions provided either by nurse, midwife or by the psychologists had little effects on the perinatal grief scores after evacuation of the abortion content, as it did not provide enough evidence on the effectiveness of the counseling sessions in improving the well-being of women after spontaneous abortion after twenty weeks of gestation.

The difference between the present study results and that of Murphy and colleagues ( 2012) ${ }^{(22)}$, may be related to the different criteria. Another cause may explain the disagreement between the findings, is the dissimilarity of the nature of intervention nature; where the present study implemented the medical professionals' guideline, while the other study stressed on counseling sessions rather than involving the woman's contact with the product of conception; that was included in the present study by allowing the woman to see the loss, hold, or even take a photo.

By assessing the total PGS scores at the three points of assessment, the present study findings showed that the total score of PGS was decreased significantly from the base line value at the two and six weeks post abortion in the intervention group. Consistent with the present study findings, Ridaura et al., (2017) ${ }^{(20)}$ found that the total score of the PGS was decreased significantly from the first assessment value at the following assessments of the intervention group participants. Also, the present study findings agreed with that of a randomized controlled trial by Johnson and Lanfford (2015) (16) which evaluated the effect of providing bereavement intervention after pregnancy loss on the grief score of post abortion women at Houston. Such study observed a significant difference of the total PGS score between the intervention group; who received the bereavement intervention according to the medical professionals' guideline, and the control group.

As well as, the present study supported that of Sriarporn et al., (2017)

(21) which found that providing counseling and support to the abortive women was an effective intervention on reducing the level of perinatal grief score on the follow up assessment at six weeks post abortion.

Regarding satisfaction with the provided care, the present study results revealed that there was a high statistical significant difference regarding satisfaction with care provided among both groups, where level of satisfaction was higher in the counseling group than that of the control group. Accordingly, the $2^{\text {nd }}$ hypothesis "“'Abortive women who receive post abortion care according to the medical professionals' guidelines, report higher satisfaction with the provided care compared to those receiving the conventional care", was enforced.

The present study results were in the same line with Tilles et al., (2016) ${ }^{(23)}$ who reported that most of the study subjects were satisfied with aspect of provided care. In another form, Chor et al .,(2015) $)^{(24)}$ conducted a study in which effect of doula support was assessed during first-trimester abortion and found that providing support by health care providers improved the overall satisfaction score with the provided care. However, Justine et al.,(2015) (25) observed that most of women in academic family medicine centers were highly satisfied with their care during abortion regardless of care approach. This agreement between the present study results and other results may be due to comprehensiveness of given care; especially attractiveness of clinical site, timely appointment, informed consent and pain management procedures.

Inversely, the present study results were in contrast with that of Lundell et al., 
(2014) (26), who assessed women perception about abortion care in Sweden and reported that young women were not satisfied with overall quality of abortion care; as there were many deficiencies in receiving a good care and effective analgesia. The disagreement between the study results and that of Lundell et al., (2014) (26) , might be due to lack of emotional support and information given post abortion and also back to the higher expectation from Sweden.

Concerning attitude of the health care providers, the current study results revealed that participants of the intervention group, positively expressed about the health care providers' attitude compared to those of the control group. The current study results were in the same line with Sriarporn et al., (2017) (21) who reported that aborted women were satisfied with the attitude of health care providers during care of abortion. Else, the current study results were consistent with Tilles $\boldsymbol{e t}$ al., (2016) ${ }^{(23)}$, who reported that majority of study subjects was satisfied with staff politeness and provided support. While, the current study findings disagreed with that of Sereshti et al., (2017) (27) , who found most women were not satisfied with health care provider's communication during abortion management.

Concerning information provided, the study results revealed a higher satisfaction among the participants of the intervention group regarding information provided, compared to those in control group. The present study results were supported by Matulich et al., (2014) (28), who assessed woman's perception about contraceptive counseling after abortion and found that ${ }^{(6)}$ the study subjects were very satisfied with information given on discharge. Contrary, Sereshti et al.,(2017) (27), reported that most women were not satisfied with information given on follow up visits and discharge recommendations; thus increasing women stress, worry, and grief scores. The difference between the study results and others may be due to lack of providing necessary information and counseling after abortion.

Conclusion and recommendations

Discharge counseling after abortion is a beneficial component of care. It has a positive impact on alleviating post abortion grief and improving woman's satisfaction with care. Accordingly, discharge counseling should be an integral part of nursing process after abortion to improve overall quality of care.

\section{References}

1. World Health Organization., (2016): Standards for improving quality of maternal and newborn care in health facilities. Number of pages: 84.Geneva,

Switzerland.Retrievedfromhttp://www .who.int/maternal_child_adolescent/d ocuments/improving-maternalnewborn-care-quality/en/.

2. Berghella, V., (2017): Obstetric Evidence-Based Guidelines $.3^{\text {rd }}$ edn. CRC Press, Taylor \& Francis Group, LLC, pp.27.

3. McKinney, E.S. James, S.R., Murry, S.S., Nelson, K.A.,and Ashwill, J.W., (2018): Maternal Child Nursing :fifth edition ;El-Ese vier ;3251 River portlane street.Lous, Misbirri 63042.ISBN :978-0-32340170-1 ;PP.523:545.

4. Cohain, J.S,. Buxban, R.E., \&Mankuta, D.E., (2017):Spontanous First Trimester Miscarriage Rates among Parous Women with one or more pregnancies of 24 weeks or more; BMC Pregnancy and Child birth ,17:437.DOI:1011861512884017-1620;PP.2:7.

5. Sedgh, G., Bearak, J., Singh, S., Bankole, A., Popinchalk, A., Ganatra ,B., et al., (2016) : Abortion incidence between 1990 and 2014:global regional ,and sub regional 
IMPLEMENTING MEDICAL PROFESSIONALS' etc...

levels and trends. Lancet 388 (10041):PP.211-306.

6. El-Nemer, A., \& Mospah, A., (2014) : Quality of maternal health care: Maternal near-misses in a university hospital, Egypt. $2^{\text {nd }}$ International Conference on Nursing \& Healthcare. November 17-19, 2014 Double Tree by Hilton Hotel Chicago-North Shore Conference Center, USA. Journal of Nursing \& Care. 3 (7),PP.78-80.

7. МOHP, WHO, Partnership for Maternal, Newborn and Child Health (PMNCH), World Bank and Alliance for Health Policy \& Systems Research (AHPSR), (2015):Success Factors for Women's and Children's Health: Egypt. Printed by

the

WHOdocument.productionservices, $\mathrm{S}$ witzerland.Retrieved.from.http://www .who.int/pmnch/successfactors/en/.

8. Ulin, K., Olsson, L.E., Wolf, A., \& Ekman, I., (2016): Person-centred care-An approach that improves the discharge process. European Journal of Cardiovascular Nursing, 15(3), PP.19-26.

9. Ackley, B. J., Ladwig, G. B., \&Flynn Makic, M. B., (2017):Nursing Diagnosis Handbook: An Evidence-Based Guide to Planning Care. $11^{\text {th }}$ edn. United States of America,, Evolve Elsevier Co, pp.215.

10. Taylor-Nyree,J.,Lederman,R., and Bosua, R., (2017):Medical record support for effective discharge planning. In Proceedings of the 25th European Conference on Information Systems (ECIS), Guimarees, Portugal, June 5-10, (pp. 2825-2833).

11.

\begin{abstract}
Durocher,E.,Gibson,B,E.,\&Rappolt, S.,(2017):Rehabilitation as "destination triage": a critical examination of discharge planning:Journal Disability and Rehabilitation. 39:(13) ,PP. 12711278.
\end{abstract}

12. Green, C. J,. (2016): Maternal Newborn Nursing Care Plans. $3^{\text {rd }}$ edn. United State of America. Jones and Bartlett Learning, LLC Co, pp. 225235.

13. Medforth, J., Ball, L., Walker, A.," Battersby, S. \& Stables, S., (2017): Oxford Textbook of Midwifery. $3^{\text {rd }}$ edn. Chapter 15, Pain relief in labour: non-pharmacological. China, Oxford University press Co, p. 296.

14. Townsed, M.C., and Margin, K.I., (2018): Psycatric Mental Health Nursing :Consept of Care in Evidance -Based Practice .Ninth edition .F.A. Davis Company 1915 Arch St.philaphedia 119103.ISBN:9780803660540;PP.867 :878.

15. Amr, S., Hassan S,I., Sad A.,( 2017): Comparison between Nursing Performance and Standard of Care for Aborted Woman at Mansoura Hospitals. IOSR Journal of Nursing and Health Science (IOSR-JNHS) eISSN: 2320-1959.p- ISSN: 2320$1940 . \quad 6:(4) . P P \quad 84-93$. www.iosrjournals.org. DOI: 10.9790/1959-0604018493.

16. Johnson, O., and Langford R., (2015): A Randomized Trial of a Bereavement Intervention for Pregnancy Loss. JOGNN, Research , 44, PP.492-499;. DOI: 10.1111/15526909.12659.

17. Bereavement Support Work team of The National SIDS and Infant Death Program Centre, (2002): Guide Lines for Medical Professionals Providing care to family experiencing perinatal loss -neonatal death, SIDS, 
or other infant death. Retrived from http:// starieges foundation .org/wpcontent /uploads guide lines for medical professionals.pdf.1-22

18. Lasker, J., Toedter, L., \&Janseen, H. (2001): International comparison of studies using the Perinatal Grief Scale: A decade of research on pregnancy loss. Death Studies, 25, PP.205-228.

19. Potvin, L., Lasker, J., and Toedter, L.,(1989): Measuring Grief :A short Version of The Perinatal Grief Scale .Journal of Psychopathology and BehavioralAssessment, (11).1, PP.2942.

20. Ridaura, I; Penelo, E.,\& Raich, R.,(2017): Depressive symptomatology and grief in Spanish women who have suffered a perinatal Loss. Psicothema, 29, (1), pp. 43-48.

21. Sriarporn, P., Turale, S., \&Lordee, N.,(2017): Support program for women suffering grief after termination of pregnancy: A pilot study; Nursing and Health Sciences 19,PP.75-80, doi: 10.1111/nhs. 12307

22. Murphy, F., Lipp, A., and ,Powles D.,(2012): Follow-up for improving psychological well-being for women after a miscarriage. Cochrane Database Systematic Review ;(3):CD008679.

23. Tilles, C., Denny, A., Cansino,C.D.,\&Creinin, M.,( 2016): Factors influencing women's satisfaction with surgical abortion; Journal of Contraception .93(5) ; PP.164-169.
24. Chor, J., Hill, B., Martin, S., Mistretta, S., Patel, A., \&Gilliam, M.,( 2015): Doula support during first-trimester surgical abortion: a randomized controlled trial. Am J Obstetric ;212(45).PP.1-6.

25. Justine, P., Emily,M., Godfrey, MD., Linda Prine, M., et al.,(2015): Women's Satisfaction With Abortion Care in Academic Family Medicine Centers(Fam Med );47(2):PP.98-106.

26. Lundell, I.,Ohman, S.,Poromaa, I., et al., (2014): How women pericieve abortion care .Study focusing on healthy women and those with mental and post traumatic stress.European Journal of contraception \&reproductive health care,20:(3),PP.211-222.

27. Sereshti, M., Nahidi, F., Simbar, M., Ahmadi,. F, Bakhtiari, M. Zayeri, F.,(2017): Mothers' Perception of Quality of Services from Health Centers after Perinatal Loss. Electronic Physician (ISSN: 2008-5842). February 2016, : 8:( 2), PP.8-18:

DOI: http://dx.doi.org/10.19082/2006

Matulich, M., Cansino, C., Culwell, KR., Creinin, MD., ;( 2014):

Understanding women's desires for contraceptive counseling at the time of first-trimester surgical abortion. Contraception ;89(2):PP.36-41 